\title{
Pengaruh Kepuasan Kerja, Self Efficacy, dan Komitmen Organisasi Terhadap Organizational Citizenship Behaviour pada PNS UPTD Unit Puskesmas Kebumen II
}

\author{
Lina Fitriyana', Nur Khasanah ${ }^{2}$ \\ 1,2Sekolah Tinggi Ilmu Ekonomi Putra Bangsa \\ Email: linafitriyana23@gmail.com ${ }^{1}$
}

\section{ARTICLE INFO}

Article History:

Received: December $7^{\text {th }} 2020$

Accepted: December $23^{\text {th }} 2020$

Published: December $31^{\text {st }} 2020$

Keywords:

Kepuasan Kerja, Self

Efficacy, Komitmen

Organisasi, Organizational

Citizenship Behaviour

\begin{abstract}
Penelitian ini bertujuan untuk menganalisis pengaruh kepuasan kerja, self efficacy dan komitmen organisasii terhadap organizational citizenship behaviour PNS. Responden pada penelitian ini adalah PNS UPTD Unit Puskesmas Kebumen II, yang berjumlah 35 responden. Penelitian ini menggunakan metode analisis deskriptif dan statistik dilakukan uji validitas, uji reabilitas, uji t, uji F, uji determinasi, dan analisis regresi linear berganda. Pengujian dalam uji $\mathrm{t}$ menunjukan bahwa variabel kepuasan kerja berpengaruh signifikan terhadap organizational citizenship behaviour PNS UPTD Unit Puskesmas Kebumen II, variabel self efficacy berpengaruh signifikan terhadap organizational citizenship behaviour PNS UPTD Unit Puskesmas Kebumen II, dan variabel komitmen organisasi berpengaruh signifikan terhadap organizational citizenship behaviour PNS UPTD Unit Puskesmas Kebumen II, kepuasan kerja, self efficacy, dan komitmen organisasi secara bersama-sama berpengaruh terhadap organizational citizenship behaviour PNS UPTD Unit Puskesmas Kebumen II.
\end{abstract}

\section{Pendahuluan}

Puskesmas adalah institusi yang pengelolaanya ditujukan untuk melayani masyarakat. Puskesmas dapat digolongkan sebagai organisasi penyedia jasa yang juga mengandalkan kualitas pelayanan jasa yang diberikan kepada masyarakat. Kecepatan pelayanan, keramahan, efektifitas tindakan serta kenyamanan bagi pasien dan pengunjung akan menjadi kunci keberhasilan dalam pengelolaan sebuah puskesmas. Sebagai sarana pelayanan kesehatan terdepan, maka puskesmas bertanggungjawab dalam menyelenggarakan pelayanan kesehatan masyarakat. Berkaitan dengan pelayanan tentunya sangat erat kaitanya dengan sumber daya manusia (SDM).

Sumber daya manusia merupakan hal yang sangat penting dalam suatu organisasi. Organisasi yang mempunyai sumber daya manusia yang baik akan mendorong munculnya Organizational Citizenship Behavior (OCB), yaitu perilaku melebihi apa yang telah distandarkan perusahaan (krietner \& kinicki 2004). Walaupun dirasakan masih langka, tetapi munculnya OCB menjadi hal yang positif bagi sebuah organisasi, tak terkecuali di UPTD unit Puskesmas Kebumen II yang merupakan salah satu unit puskesmas di Kebumen yangberada di Desa Jatisari Kecamatan Kebumen. Munculnya OCB dapat menjadi gambaran adanya kinerja yang tinggi dalam organisasi. 
Perilaku pegawai yang memiliki OCB yang tinggi tidak hanya menampilkan perilaku in role atau hanya yang sesuai dengan imbalan yang diperolehnya saja tetapi mereka terkadang bekerja melebihi apa yang seharusnya dilakukan atau perilaku extra role yang biasa disebut organizational citizenship behaviour (OCB). Hasil observasi dan wawancara awal terhadap pihak puskesmas Kebumen II diperoleh informasi bahwa OCB disana sudah cukup baik, adanya perilaku ekstra roll yang ditampilkan oleh pegawai dengan melakukan aktivitas-aktivitas kerja yang melebihi tugas pekerjaan yang telah ditetapkan, yaitu memberikan pelayanan ekstra kepada pasien, seperti bidan desa yang bersedia memberikan pelayanan ke desa lain bila rekanya sedang berhalangan, bagian pelayanan dan pendaftaran yang masih mau melayani ketika sudah melebihi jam pelayanan, bagian tata usaha (TU) yang bersedia pulang diatas jam kerja dengan suka rela tanpa dihitung lembur. Petugas piket bagian persalinan yang bersedia bertukar shift kerja dan menggantikan rekanya bila tidak masuk. Bahkan Puskesmas Kebumen II ditahun 2017 pernah memperoleh juara III tingkat provinsi Jawa Tengah dalam hal pelayanan kesehatan (FKTP).

Organizational Citizenship behavior dapat timbul dari berbagai faktor dalam organisasi, diantaranya karena adanya kepuasan kerja dari karyawan dan komitmen organisasi yang tinggi (Robbin \& Judge, 2007), apabila karyawan merasakan kepuasan terhadap pekerjaan yang dilakukanya, maka karyawan tersebut akan bekerja secara maksimal dalam menyelesaikan pekerjaanya, bahkan melakukan beberapa hal yang mungkin diluar tugasnya, ketika karyawan saja tidak mengalami kepuasan maka pelayanan yang diberikan kepada konsumen, dalam hal ini pasien yang datang ke Puskesmas bisa tidak memuaskan. Kepuasan kerja tidak hanya penting sebagai dorongan utama tetapi juga berpengaruh terhadap semangat kerja pegawai. Kepuasan kerja diartikan sebagai tanggapan emosional seseorang terhadap aspek-aspek di dalam atau pada keseluruhan pekerjaanya (Nawawi, 1998). Keadaan emosional atau sikap seseorang tersebut akan diperlihatkan dalam bentuk tanggung jawab, perhatian, serta perkembangan kinerjanya. Murphy, Athanasou, Raja (2002), Begun (2006), Zeinabadi (2010) kepuasan kerja berpengaruh signifikan pada OCB, temuan ini sesuai dengan hasil penelitian dari Salehi dan Gholtash (2011) terdapat ada hubungan positif antara kepuasan kerja dan OCB. Kepuasan kerja adalah hasil dari persepsi karyawan tentang seberapa baik pekerjaan seseorang memberikan segala sesuatu yang dipandang sebagai sesuatu yang penting melalui pekerjaan mereka (Luthans, 2011), Robbin (2006) menemukan bahwa kepuasan kerja adalah refrensi dari sikap umum individu terhadap pekerjaanya. Seseorang dengan tingkat kepuasan yang tinggi menunjukan sikap positif terhadap pekerjaan. Fitzgerald et al (1994 di Crossman, dan Bassem, 2003) mengungkapkan bahwa kepuasan kerja adalah emosi positif yang dihasilkan dari perasaan nyaman setiap karyawan saat melakukan pekerjaan.

Berdasarkan observasi awal penulis yang dilakukan pada PNS UPTD Unit Puskesmas Kebumen II bahwa kepuasan kerja pegawai disana sudah cukup baik karena pegawai merasa mempunyai rekan kerja yang menyenangkan dan kondisi lingkungan kerja yang baik sehingga menciptakan kenyamanan bagi pegawai dan memudahkan pegawai untuk bekerja, karena pegawai menganggap bahwa bekerja merupakan sarana memenuhi kebutuhan untuk berinteraksi sosial, sehingga rekan kerja yang menyenangkan dan mendukung dapat meningkatkan kepuasan kerja, selain itu pegawai juga merasa puas karena pimpinan yang bersikap ramah, dapat memahami dan mau mendengarkan pendapat pegawai. Sistem gaji dan kebijakan promosi yang adil dan sesuai dengan harapan pegawai juga menjadi kepuasan tersendiri bagi pegawai.

Faktor lain yang mempengaruhi organizational citizenship behaviour yaitu self efficacy. Self efficacy merupakan salah satu aspek pengetahuan tentang diri atau self knowledge yang paling berpengaruh dalam kehidupan manusia sehari-hari. Hal ini disebabkan efikasi diri yang 
dimiliki ikut mempengaruhi individu dalam menentukan tindakan yang akan dilakukan untuk mencapai suatu tujuan termasuk di dalamnya perkiraan berbagai kejadian yang akan dihadapi. Self efficacy yakni keyakinan bahwa seseorang bisa menguasai situasi dan mendapatkan hasil positif. Bandura (Santrock, 2007:286) mengatakan bahwa efikasi diri berpengaruh besar terhadap perilaku. Bandura (1994:2) dengan teori efikasi diri baik individu ataupun kolektif memiliki fokus pada keyakinan akan kemampuan dan diaktualkan dengan perilaku atau kinerja yang bertujuan untuk mencapai tujuan. Copper (2010) menjelaskan bahwa kontruksi dari self efficacy adalah teori sosial kognitif dan hubungan antar manusia dari hubungan sebab akibat dan timbal balik. Kenyataan yang terlihat di UPTD Unit Puskesmas Kebumen II sebagian besar pegawai memiliki self efficacy yang cukup baik karena pegawai tidak mudah menyerah dan putus asa dalam mengatasi masalah, selalu yakin bisa menyelesaikan tugas yang diberikan oleh pimpinan secara tepat waktu, tidak merasa ragu dan takut bila dihadapkan pada tantangan baru dalam pekerjaan. Selain self efficacy seseorang yang mempunyai komitmen yang tinggi terhadap organisasinya akan melakukan apapun untuk memajukan perusahaanya karena keyakinanya terhadap organisasinya (Luthans, 1994).

Seorang pegawai yang mempunyai komitmen organisasi yang tinggi akan cenderung menampilkan OCB yang tinggi pula, pegawai yang memiliki komitmen organisasi yang tinggi cenderung memiliki sikap bersedia menyelesaikan pekerjaannya hingga tuntas dan memiliki serta menjalankan prinsip-prinsip etika dalam melakukan pekerjaanya, cenderung tidak terpengaruh jika rekan kerjanya mendapatkan hak istimewa dari atasan yang tidak didapatkan olehnya, tetap antusias dan sukarela mengambil tanggungjawab ekstra dalam pekerjaan. Menurut Griffin (2004), komitmen organisasi adalah sikap yang mencerminkan sejauh mana seseorang individu mengenal dan terikat pada organisasinya. Seseorang individu yang memiliki komitmen tinggi kemungkinan akan melihat dirinya sebagai anggota sejati organisasi. Sedangkan menurut Robbins dan Judge (2007) komitmen organisasi didefinisikan sebagai keterlibatan pekerjaan yang tinggi pada pekerjaan tertentu seseorang individu. Komitmen organisasional yang tinggi berarti memihak organisasi yang merekrut individu tersebut.

Sikap komitmen organisasi di UPTD unit Puskesmas Kebumen II tergambar dari perilaku pegawai yang menganggap organisasi (Puskesmas) sebagai salah satu bagian dari diri mereka untuk mencurahkan perhatianya secara totalitas demi tercapainya visi misi, selain itu ada keinginan untuk terus berada di organisasi tersebut tanpa ada niatan untuk pindah tempat kerja.

\section{Kajian Teori dan Telaah Literatur}

\section{Kepuasan kerja}

Kepuasan kerja adalah hasil dari persepsi karyawan mengenai seberapa baik pekerjaan mereka memberikan hak yang dinilai penting (Luthans, 2009). Smith et al (1969) menyebutkan indikator kepuasan kerja antara lain:

1) Pembayaran (pay)

2) Pekerjaan $(j o b)$

3) Kesempatan promosi (promotion oportunities)

4) Atasan (supervisor)

5) Rekan kerja (Co-workers)

\section{Self efficacy}

Self efficacy adalah penilaian seseorang terhadap dirinya sendiri atau tingkat keyakinan mengenai seberapa besar kemampuannya dalam mengerjakan suatu tugas tertentu untuk 
mencapai hasil tertentu Woolfolk (Anwar, 2009:23) indikator Self efficacy (Bandura, dalam anwar 2009) antara lain:

1) Tingkat (Level)

2) Kekuatan (strength)

3) Generalisasi (generality)

\section{Komitmen organisasi}

Komitmen organisasi adalah derajat yang mana pegawai percaya dan menerima tujuantujuan organisasi sopiah (2008). Berdasarkan penelitian Allen dan Mayer (1997) ketiga komponen menyebabkan berbagai konsekuensi yang berbeda dengan perilaku kerja, dasar dari argument tersebut konsekuensinya berbeda pada masing-masing komponen komitmen

1) Affective Commitment

2) Continuance Commitment

3) Normative Commitment

\section{Organizational citizenship behaviour}

Organizational Citizenship Behavior (OCB), yaitu perilaku melebihi apa yang telah distandarkan perusahaan (krietner \& kinicki 2004). Dimensi pengukuran variabel ini ada lima indikator, mengutip dari Organ (1988) yaitu :

1) Altruism

2) Civic Virtue

3) Conscientiousness

4) Courtesy

5) Sportsmanship

\section{Metode Penelitian}

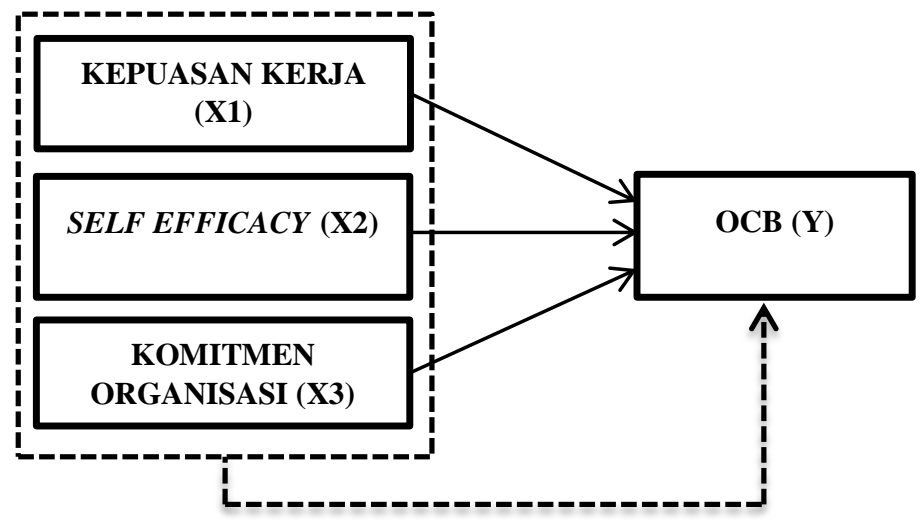

Gambar 1. Model Empiris

Berdasarkan kerangka penelitian dalam hipotesis penelitian ini dirumuskan sebagai berikut: $\mathrm{H}_{1}$ : Kepuasan kerja berpengaruh signifikan terhadap Organizational Citizenship Behavior $\mathrm{H}_{2}$ : Self efficacy berpengaruh signifikan terhadap Organizational Citizenship Behavior $\mathrm{H}_{3}$ : Komitmen organisasi berpengaruh signifikan terhadap Organizational Citizenship Behavior $\mathrm{H}_{4}$ : Kepuasan kerja, self efficacy, dan komitmen organisasi secara bersama-sama berpengaruh terhadap Organizational Citizenship Behavior 


\section{Hasil dan Pembahasan}

\section{Uji Validitas}

Uji validitas digunakan untuk mengukur sah atau valid tidaknya suatu kuesioner (Ghozali, 2009:49). Berdasarkan hasil uji validitas pada variabel kepuasan kerja, self efficacy , komitmen organisasi dan OCB PNS menunjukan bahwa pada kolom $r_{\text {hitung }}$ lebih besar dari nilai $r_{\text {tabel }}$ $(0,3338)$ dengan signifikansi lebih kecil dari 0,05 sehingga dapat disimpulkan bahwa semua butir instrument pada kuesioner variabel kepuasan kerja,self efficacy , komitmen organisasi dan OCB PNS yaitu valid.

\section{Uji Reliabilitas}

Reliabilitas adalah alat untuk mengukur suatu kuesioner yang merupakan indikator dari variabel atau konstruk (Ghozali, 2009:45). Berdasarkan hasil uji reliabilitas menunjukan bahwa nilai croncbach alpha untuk variabel kepuasan kerja 0,893, variabel self effiacacy 0,871, variabel komitmen organisasi 0,887 , serta untuk variabel OCB PNS 0,868. Berdasarkan hasil perhitungan tersebut, dapat dinyatakan bahwa seluruh pernyataan pada semua variabel penelitian dinyatakan reliable karena nilai Cronbach alpha diatas 0,60.

\section{Uji Asumsi Klasik}

\section{Uji Multikolonieritas}

Menurut Ghozali (2013:105) uji multikolinearitas bertujuan untuk menguji apakah model regresi ditemukan adanya korelasi antar variabel bebas.

Tabel 1. Uji Multikolinieritas

\begin{tabular}{llll}
\hline No & Variabel & \multicolumn{2}{l}{ Colinieritas Statistic } \\
& & Tolerance & VIF \\
\hline 1 & Kepuasan kerja & 0,798 & 1,253 \\
2 & Self efficacy & 0,736 & 1,358 \\
3 & Komitmen & 0,914 & 1,094 \\
& organisasi & & \\
\hline
\end{tabular}

Sumber: Data primer diolah (2020)

Berdasarkan Tabel 1, dapat diketahui bahwa nilai tolerance diatas 0,01 dan nilai VIF dibawah 10 sehingga model regresi tidak terjadi multikolonieritas. 


\section{Uji Heteroskedastisitas}

Menurut Ghozali (2013:139), uji heteroskedastisitas bertujuan menguji apakah dalam model regeresi terjadi ketidaksamaan variance dan residual dari satu pengamatan ke pengamatan yang lain.

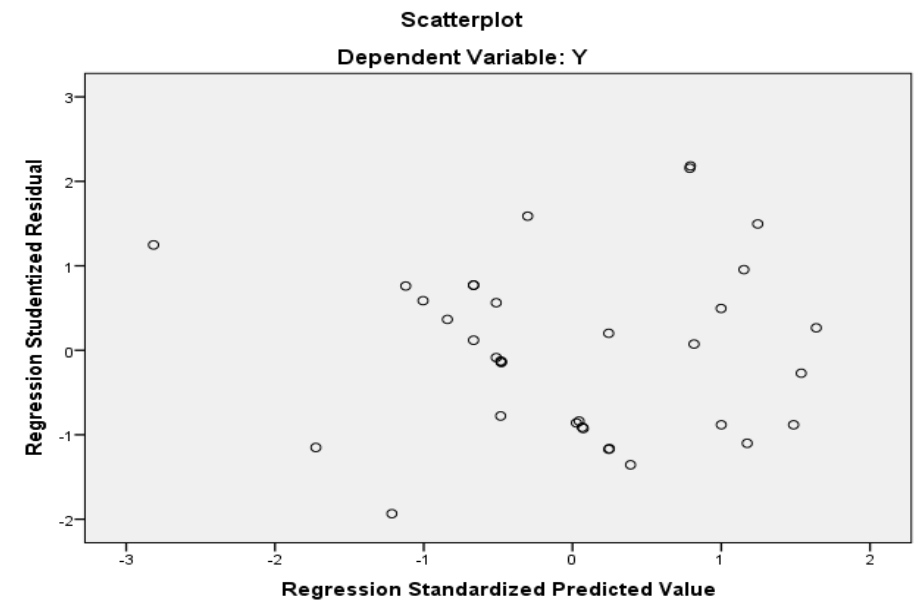

Sumber: Data primer diolah (2020)

Gambar 2. Uji Heteroskedastisitas

Berdasarkan Gambar 2, menunjukan bahwa tidak ada pola tertentu yang berupa titik-titik yang membentuk pola teratur dan tidak terdapat pola yang jelas sehingga dapat disimpulkam bahwa model regresi pada penelitian ini tidak terjadi heteroskedatisitas.

\section{Uji Normalitas}

Menurut Ghozali (2013:160), uji normalitas bertujuan untuk menguji apakah dalam model regresi, variabel pengganggu atau residual memiliki distribusi normal. Untuk menguji suatu data berdistribusi normal atau tidak, dapat diketahui dengan menggunakan garfik normal plot (Ghozali, 2009:147)

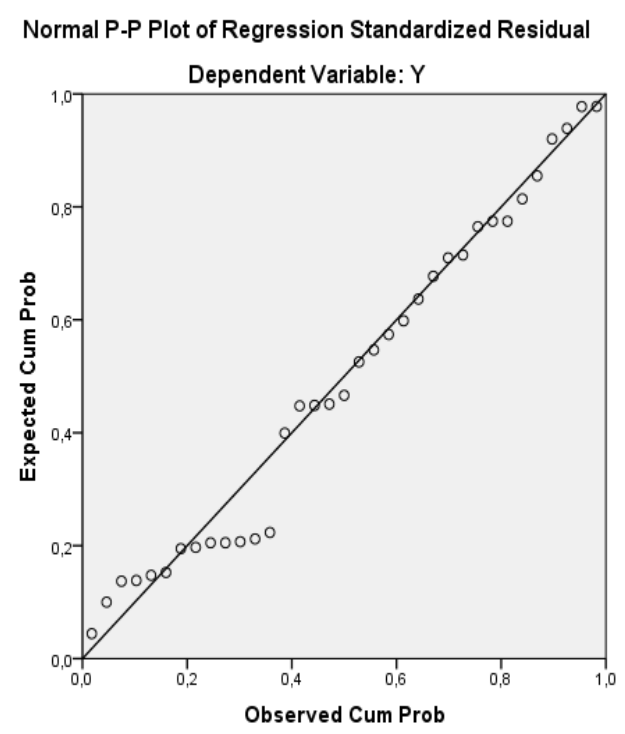

Sumber: Data primer diolah (2020)

Gambar 3. Uji Normalitas 
Berdasarkan Gambar 3 hasil uji normalitas diatas diketahui bahwa titik menyebar disekitar garis diagonal dan mengikuti arah garis diagonal, maka model regresi tersebut memenuhi asumsi nomalitas.

\section{Uji Regresi Linear Berganda}

Tabel 2. Hasil Analisis Regresi Berganda

\begin{tabular}{cccc}
\hline \multicolumn{2}{c}{$\begin{array}{c}\text { Unstandardized } \\
\text { Coefficients }\end{array}$} & $\begin{array}{c}\text { Standardized } \\
\text { Coefficients }\end{array}$ & $\mathrm{T}$ \\
\cline { 1 - 3 } B & Std. Error & Beta & \\
\hline, 587 & 2,443 & &, 240 \\
, 378 &, 110 &, 404 & 3,435 \\
, 391 &, 134 &, 357 & 2,920 \\
, 317 &, 093 &, 373 & 3,397 \\
\hline \multicolumn{2}{l}{ Sumber: Data primer diolah (2020) }
\end{tabular}

Berdasarkan tabel 2, maka dapat dibuat persamaan regresi antara lain sebagai berikut:

$$
\begin{aligned}
Y & =a+b_{1} X_{1}+b_{2} X_{2}+b_{3} X_{3}+e \\
& =0,587+0,378+0,391+0,317+e
\end{aligned}
$$

Keterangan:

$$
\begin{array}{ll}
\mathrm{Y} & =\text { OCB PNS } \\
\mathrm{a} & =\text { Konstanta } \\
\mathrm{b}_{1}, \mathrm{~b}_{2}, \mathrm{~b}_{3} & =\text { Koefisien regresi variabel independen } \\
\mathrm{X}_{1} & =\text { Kepuasan kerja } \\
\mathrm{X}_{2} & =\text { self efficacy } \\
\mathrm{X}_{3} & =\text { komitmen organisasi }
\end{array}
$$

Persamaan diatas dapat dijelaskan antara lain sebagai berikut:

a) Konstanta sebesar 0,587 menunjukan bahwa jika nilai kepuasan kerja, self efficacy, dan komitmen organisasi $=0$ maka, nilai variabel OCB PNS sebesar 0,587.

b) Koefisien variabel kepuasan kerja sebesar 0,378 menunjukan bahwa apabila variabel kepuasan kerja berubah 1 satuan, akan menimbulkan perubahan OCB PNS sebesar 0,378 satuan dengan asumsi bahwa variabel independen yang lain konstan.

c) Koefisien variabel self efficacy sebesar 0,391 menunjukan bahwa apabila variabel self efficacy berubah 1 satuan, akan menimbulkan perubahan OCB PNS sebesar 0,391 satuan dengan asumsi bahwa variabel independen yang lain konstan.

Koefisien variabel komitmen organisasi sebesar 0,317 menunjukan bahwa apabila variabel komitmen organisasi berubah 1 satuan, akan menimbulkan perubahan OCB PNS sebesar 0,317 satuan dengan asumsi bahwa variabel independen yang lain konstan 


\section{Uji Hipotesis}

\section{Uji t (Uji Parsial)}

Tabel 3. Hasil Analisis Uji t

\begin{tabular}{cllll}
\hline Variabel & Sig. & $\boldsymbol{A}$ & $\mathbf{t}$ hitung & $\mathbf{t}$ tabel \\
\hline $\mathbf{X}_{\mathbf{1}}$ & 0,002 & 0,05 & 3,435 & 2,040 \\
$\mathbf{X}_{\mathbf{2}}$ & 0,006 & 0,05 & 2,920 & 2,040 \\
$\mathbf{X}_{\mathbf{3}}$ & 0,002 & 0,05 & 3,397 & 2,040 \\
\cline { 2 - 3 } Sumber: & Data primer diolah (2020) & &
\end{tabular}

Tabel 3 menunjukan menunjukan hal-hal sebagai berikut:

Probabilitas signifikan variabel pengetahuan $\left(X_{1}\right)$ sebesar $0,002<0,05$ dan hasil perhitung diperoleh angka sebesar $3.435>$ 2,040 yang berarti kepuasan kerja berpengaruh signifikan terhadap variabel (Y) atau OCB PNS UPTD Unit Puskesmas Kebumen II.

Pada probabilitas signifikan variabel self efficacy $\left(X_{2}\right)$ sebesar 0,006 $<0,05$ dan hasil perhitungan diperoleh angka sebesar 2,920 > 2,040 yang berarti self efficacy berpengaruh signifikan terhadap variabel (Y) atau OCB PNS UPTD Unit Puskesmas Kebumen II.

Probabilitas signifikan variabel komitmen organisasi $\left(X_{3}\right)$ sebesar 0,002 < 0,05 dan hasil perhitungan diperoleh sebesar 3,397 > 2,040 yang berarti komitmen organisasi berpengaruh signifikan terhadap variabel (Y) atau OCB PNS UPTD Unit Puskesmas Kebumen II.

\section{Uji F (Uji Simultan)}

Tabel 4. Hasil Analisis Uji F

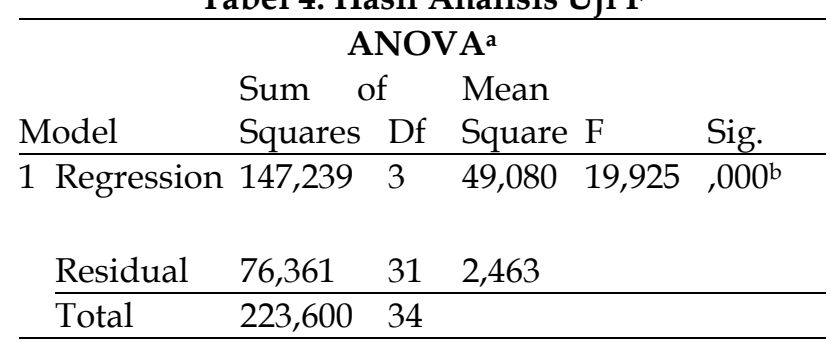

a. Dependent Variable: Total Y

b. Predictors: (Constant), X3, X1, X2

Sumber: Data primer diolah (2020)

Berdasarkan tabel 4 diatas dapat diketahui bahwa nilai $\mathrm{F}$ hitung sebesar 19,925 dengan signifikan 0,000 $<0,05$ dan lebih kecil dari $a=0,05$ dan F hitung sebesar 19,925 lebih besar dari $\mathrm{F}$ tabel sebesar 2,90, sehingga dapat disimpulkan bahwa secara bersama-sama kepuasan kerja, self efficacy, dan komitmen organisasi berpengaruh terhadap organizational citizenship behaviour pada PNS UPTD Unit Puskesmas Kebumen II. 


\section{Koefisien Determinasi ( $\left.\mathbf{R}^{2}\right)$}

Tabel 5. Uji Koefisien Determinasi $\left(\mathbf{R}^{2}\right)$

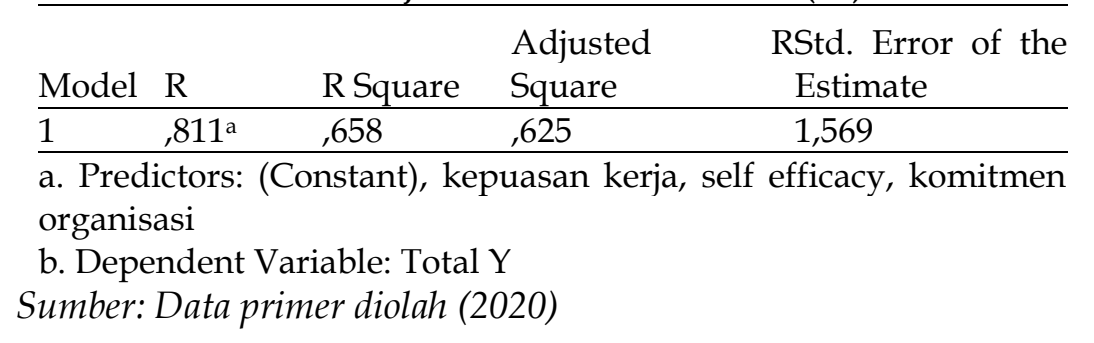

Berdasarkan tabel 5 diatas menunjukan bahwa pada kolom $R$ Square diperoleh nilai sebesar 0,658 atau $65,8 \%$. Hal ini berarti bahwa kepuasan kerja, self efficacy, dan komitmen organisasi berpengaruh terhadap OCB PNS sebesar 65,8\% dimana $(100 \%-65,8 \%=34,2 \%)$. Sedangkan sisanya sebesar $34,2 \%$ OCB dipengaruhi oleh variabel lainnya yang tidak diteliti dalam penelitian ini.

\section{Pembahasan}

\section{Pengaruh kepuasan kerja terhadap organizational citizhenship behaviour}

Pengujian hipotesis pertama dilakukan untuk mengetahui pengaruh kepuasan kerja terhadap organizational citizenship behaviour PNS UPTD Unit Puskesmas Kebumen II. Berdasarkan hasil analisis pada variabel kepuasan kerja, diperoleh nilai koefisien beta pada pengaruh kepuasan kerja terhadap organizational citizenship behaviour sebesar 0,3435 atau $34,3 \%$ dengan nilai $t$ hitung sebesar 2,040 dan signifikansi sebesar 0,002 sehingga menghasilkan keputusan bahwa hipotesis pertama diterima. Artinya apabila karyawan memiliki tingkat kepuasan kerja yang tinggi dapat meningkatkan organizational citizenship behaviour pada organisasi.

Hasil penelitian ini sejalan dengan penelitian terdahulu ynag dilakukan oleh oleh Dian Puspita Rini (2013) dengan judul penelitian "pengaruh komitmen organisasi, kepuasan kerja, dan budaya organisasi terhadap organizational citizenship behaviour studi pada PT. Plasa Simpanglima Semarang" yang menyatakan bahwa kepuasan kerja berpengaruh signifikan terhadap organizational citizenship behaviour.

\section{Pengaruh self efficacy terhadap organizational citizhenship behaviour}

Pengujian hipotesis kedua dilakukan untuk mengetahui pengaruh self efficacy terhadap organizational citizenship behaviour pada PNS UPTD Unit Puskesmas Kebumen II. Berdasarkan hasil analisis pada variabel self efficacy diperoleh nilai koefisien beta pada pengaruh self efficacy terhadap organizational citizenship behaviour sebesar 0,2920 atau 29,2\% dengan nilai $t$ hitung sebesar 2,040 dan nilai signifikansi sebesar 0,006 sehingga menghasilkan keputusan bahwa hipotesis kedua diterima. Hasil pengujian hipotesis menunjukan bahwa variabel self efficacy memiliki pengaruh yang signifikan terhadap organizational citizenship behaviour PNS Puskesmas Kebumen II, hal ini mengidentifikasikan bahwa pegawai yang memiliki keyakinan diri yang kuat dan merasa mampu dalam mengerjakan tugas pekerjaanya maka mereka akan bekerja dengan maksimal dan melibihi apa yang telah di standarkan perusahaan.

Hasil penelitian ini sejalan dengan penelitian yang dilakukan oleh Ni Made Syntia Dewi, I Gede Adnyana Sudibya (2016) dengan judul penelitian "Pengaruh efikasi diri terhadap organizational citizenship behaviour dengan kepuasan kerja sebagai variabel mediasi pada PLN 
(rayon) Denpasar" dengan hasil penelitian menunjukan bahwa efikasi diri berpengaruh terhadap organizational citizenship behaviour yang dipengaruhi oleh kepuasan kerja.

\section{Pengaruh Komitmen organisasi terhadap organizational citizhenship behaviour}

Hasil Pengujian hipotesis ketiga dilakukan untuk mengetahui pengaruh komitmen organisasi terhadap organizational citizenship behaviour pada PNS UPTD Unit Puskesmas Kebumen II. Berdasarkan hasil analisis pada variabel komitmen organisasi diperoleh nilai koefisien beta sebesar 0,3937 atau 39,3\% dengan nilai thitung sebesar 2,040 dan signifikansi sebesar 0,002 sehingga menghasilkan keputusan bahwa hipotesis ketiga diterima. pengujian hipotesis menunjukan bahwa variabel komitmen organisasi memiliki pengaruh yang signifikan terhadap organizational citizenship behaviour pada PNS Puskesmas Kebumen II. Artinya bahwa apabila pegawai memiliki komitmen organisasi yang tinggi dapat meningkatkan organizational citizenship behaviour pada PNS Puskesmas Kebumen II, hal ini mengidentifikasikan bahwa pegawai yang komitmenya tinggi akan memberikan yang terbaik bagi organisasinya dan bekerja dengan sungguh-sungguh bahkan melibihi apa yang telah di standarkan oleh organisasi.

Hasil penelitian sejalan dengan penelitian terdahulu yang dilakukan oleh A Ngurah Bagus Danendra dan Ni Wayan Mujiati (2016) dengan judul penelitian "Pengaruh motivasi, kompensasi, dan komitmen organisasional terhadap Organizational Citizenship Behaviour (OCB) pada karyawan PT Harapan Baru Denpasar". Yang menyatakan dalam penelitiannya komitmen organisasi berpengaruh positif dan signifikan terhadap organizational citizenship behaviour.

\section{Simpulan}

Berdasarkan hasil analisis data yang terkumpul dari kuisioner mengenai pengaruh kepuasan kerja, self efficacy, dan komitmen organisasi terhadap organizational citizenship behavior pada PNS UPTD Unit Puskesmas Kebumen II dapat disimpulkan sebagai berikut:

1) Berdasarkan hasil pengujian secara parsial variabel kepuasan kerja berpengaruh secara signifikan terhadap organizational citizenship behavior pada PNS UPTD Unit Puskesmas Kebumen II. Hal ini dibuktikan dari nilai signifikansi lebih kecil dibandingkan nilai signifikansi yang ditentukan yaitu 0,002 <0,05. Hal ini menunjukan bahwa kepuasan kerja berpengaruh signifikan terhadap organizational citizenship behavior. Artinya semakin tinggi kepuasan kerja yang diterima pegawai maka akan semakin tinggi pula organizational citizenship behavior yang dimiliki.

2) Berdasarkan hasil pengujian secara parsial variabel self efficacy berpengaruh secara signifikan terhadap organizational citizenship behavior pada PNS UPTD Unit Puskesmas Kebumen II. Hal ini diibuktikan dari nilai signifikansi lebih kecil dibandingkan dengan nilai signifikansi yang ditentukan yaitu 0,006 <0,05. Artinya semakin tinggi self efficacy maka akan semakin tinggi pula organizational citizenship behavior yang dimilki oleh pegawai.

3) Berdasarkan hasil pengujian secara parsial variabel komitmen organisasi berpengaruh secara signifikan terhadap organizational citizenship behavior pada PNS UPTD Unit Puskesmas Kebumen II. Hal ini diibuktikan dari nilai signifikansi lebih kecil dibandingkan dengan nilai signifikansi yang ditentukan yaitu 0,002 $<0,05$. Artinya semakin tinggi komitmen organisasi yang dimilki oleh pegawai maka akan semakin tinggi pula organizational citizenship behavior yang ditampilkan.

4) Berdasarkan hasil penelitian menunjukan bahwa kepuasan kerja, self effiacacy, dan komitmen organisasi secara simultan berpengaruh signifikan terhadap organizational 
citizenship behavior pada PNS UPTD Unit Puskesmas Kebumen II. Hal ini dibuktikan dari nilai signifikansi yang diperoleh bernilai positif sehingga hal ini menunjukan bahwa secara simultan atau secara bersama-sama kepuasan kerja, self effiacacy, dan komitmen organisasi berpengaruh signifikan terhadap organizational citizenship behavior Artinya semakin besar kepuasan kerja, self effiacacy, dan komitmen organisasi secara bersamasama akan semakin besar pula organizational citizenship behavior yang dimiliki oleh PNS UPTD Unit Puskesmas Kebumen II.

5) Berdasarkan hasil pengujian koefisien determinasi variabel kepuasan kerja, self effiacacy, dan komitmen organisasi mempengaruhi organizational citizenship behavior PNS UPTD Unit Puskesmas Kebumen II sebesar 65,8\% sedangkan sisanya 34,2\% dipengaruhi oleh variabel lain yang tidak ada dalam model regresi linear

\section{Referensi}

Allen, N.J., \& Mayer, J.P. 1990 "The Measurement and Antecedents of Affective,Continuance and Normative Commitment to the Organization". Journal ofOccupational Psychology, No. 63: $1-18$.

Bandura, A., \& Locke, E. A. (2003). Negative self-efficacy and goal effects revisited. Journal of applied psychology, 88(1), 87-99.

Ghozali, I. (2009). Aplikasi Analisis Multivariate dengan Program SPSS. Semarang: Penerbit Universitas Dipenogoro.

Ghozali, I. (2013). Aplikasi Analisis Multivariat dengan Program IBM SPSS. Edisi 7. Semarang: Penerbit Universitas Diponegoro.

Griffin, R. W. (2004). Komitmen Organisasi. Terjemahan. Jakarta: Erlangga.

Krietner, R., \& Kinicki, R. (2004) Organizational Behavior, 6th Edition. New York: Mcgrawhill.

Luthans, F. (2011). Organizational Behavior: An Evidence-Based Ahlmroach,12thEdition). New York : Macgraw-Hill.

Murphy, G., Athanasou, J., \& King, N. (2002). Job satisfaction and organizational citizenship behaviour: A study of Australian human-service professionals. Journal of managerial Psychology, 14(4), 287-297.

Organ, D. W. (1988). Organizational Citizenship Behavior: The Good Soldie syndromeLexington, Ma: Lexington Books.

Robbins, S. P. (1996). Organization Behavior: Concep-Contraversies Application. NewJersey: Englewood Cliffs: Prentice-Hall, Inc.

Zeinabadi, H. 2010. Kepuasan kerja dan komitmen organisasi sebagai anteseden OCB guru.Procedia Sosial dan Ilmu Perilaku, 5, 998-1003. 